OPEN ACCESS

Edited by:

Marit Van Gils,

Academic Medical Center,

Netherlands

Reviewed by:

Simone Richardson,

National Institute of Communicable

Diseases (NICD), South Africa

Lars Hangartner,

The Scripps Research Institute,

United States

*Correspondence: Alejandro Benjamin Balazs abalazs@mgh.harvard.edu

Specialty section:

This article was submitted to

Vaccines and Molecular

Therapeutics,

a section of the journal

Frontiers in Immunology

Received: 30 June 2021

Accepted: 24 August 2021 Published: 15 September 2021

Citation:

Phelps M and Balazs AB (2021) Contribution to HIV Prevention and

Treatment by Antibody-Mediated

Effector Function and Advances in

Broadly Neutralizing Antibody Delivery

by Vectored Immunoprophylaxis.

Front. Immunol. 12:734304.

doi: 10.3389/fimmu.2021.734304

\section{Contribution to HIV Prevention and Treatment by Antibody- Mediated Effector Function and Advances in Broadly Neutralizing Antibody Delivery by Vectored Immunoprophylaxis}

\author{
Meredith Phelps and Alejandro Benjamin Balazs* \\ Ragon Institute of MGH, MIT and Harvard, Cambridge, MA, United States
}

HIV-1 broadly neutralizing antibodies (bNAbs) targeting the viral envelope have shown significant promise in both HIV prevention and viral clearance, including pivotal results against sensitive strains in the recent Antibody Mediated Prevention (AMP) trial. Studies of bNAb passive transfer in infected patients have demonstrated transient reduction of viral load at high concentrations that rebounds as bNAb is cleared from circulation. While neutralization is a crucial component of therapeutic efficacy, numerous studies have demonstrated that bNAbs can also mediate effector functions, such as antibodydependent cellular cytotoxicity (ADCC), antibody-dependent cellular phagocytosis (ADCP), and antibody-dependent complement deposition (ADCD). These functions have been shown to contribute towards protection in several models of HIV acquisition and in viral clearance during chronic infection, however the role of target epitope in facilitating these functions, as well as the contribution of individual innate functions in protection and viral clearance remain areas of active investigation. Despite their potential, the transient nature of antibody passive transfer limits the widespread use of bNAbs. To overcome this, we and others have demonstrated vectored antibody delivery capable of yielding long-lasting expression of bNAbs in vivo. Two clinical trials have shown that adeno-associated virus (AAV) delivery of bNAbs is safe and capable of sustained bNAb expression for over 18 months following a single intramuscular administration. Here, we review key concepts of effector functions mediated by bNAbs against HIV infection and the potential for vectored immunoprophylaxis as a means of producing bNAbs in patients.

Keywords: vectored immunoprophylaxis, HIV, broadly neutralizing antibody, VRC07, humanized mice, AAV, Fc receptor, innate immunity 


\section{INTRODUCTION}

Despite the success of pre-exposure prophylaxis (PrEP) and antiretroviral therapy (ART) in reducing HIV incidence in developed countries, the HIV pandemic remains a major burden in developing nations (1). Among the novel interventions that continue to be developed, those employing broadly neutralizing antibodies are among the most promising as potential prevention (2), therapeutic (3) or cure modality via elimination of the latent viral reservoir (4). Broadly neutralizing antibodies (bNAbs) are defined by their capacity for potent neutralization of large panels of diverse strains (5-8). Numerous studies in non-human primates (NHP) and humanized mice have explored the potential for passive transfer of various bNAbs to prevent HIV acquisition. Testing of various antibodies has shown that bNAb-mediated prevention can be highly effective, however, at low concentrations a loss of protection against challenge is observed (9-11).

In addition to direct neutralization of virus entry, antibodies are capable of mediating non-neutralizing functions that are important in the context of HIV prevention and viral clearance, such as antibody-dependent cellular cytotoxicity (ADCC), antibody-dependent cellular phagocytosis (ADCP) and antibody-dependent complement deposition (ADCD), through engagement of the Fragment crystallizable $(\mathrm{Fc})$ region with various Fc receptors expressed on the surface of innate cells or complement proteins in the circulation (Figure 1) (12-16). Therefore, understanding the parameters that influence bNAb

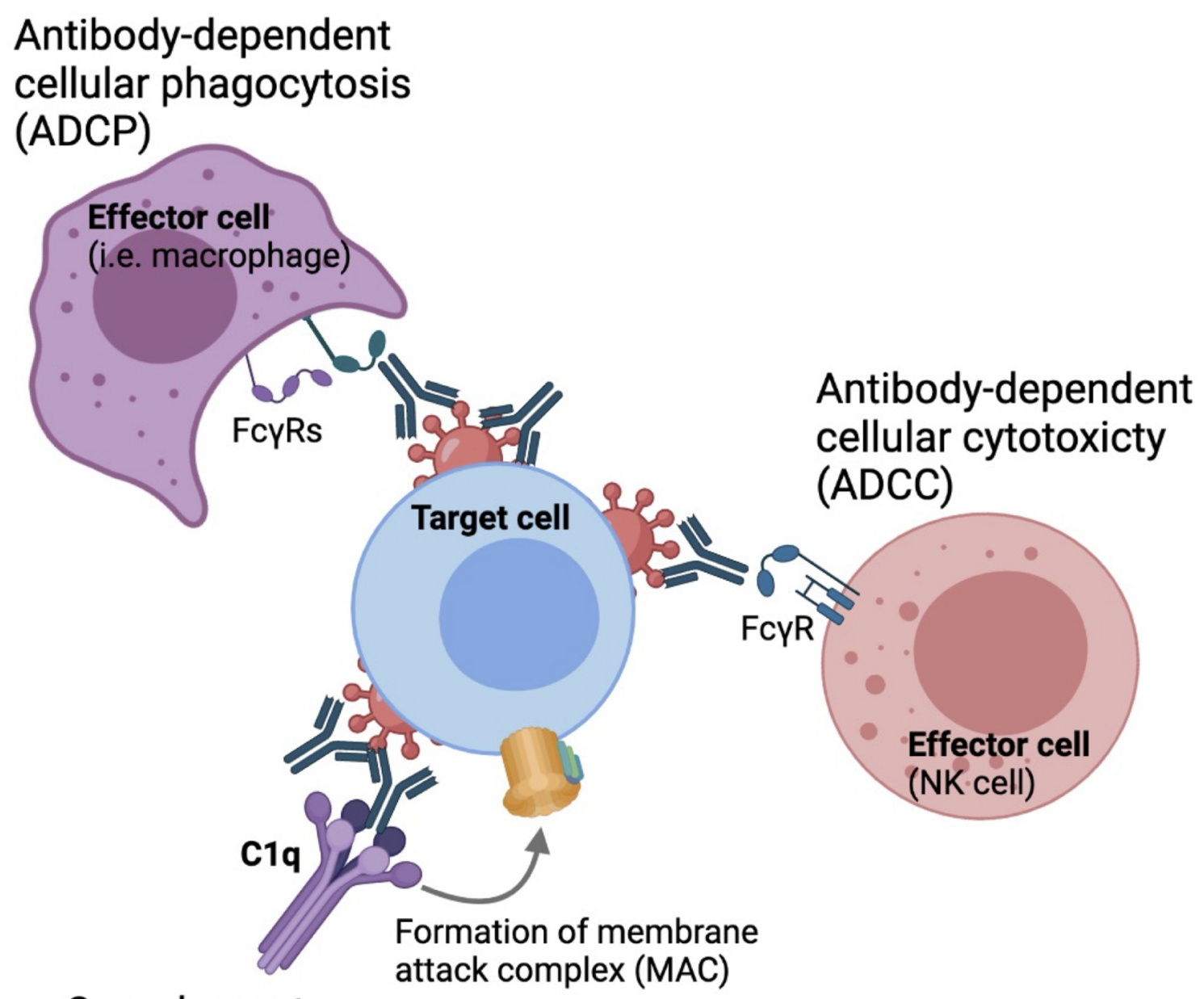

Complement dependent cytotoxity (CDC)

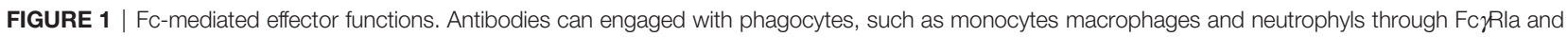

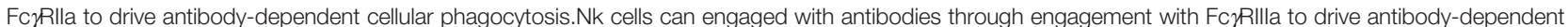
cellular cytotoxicity. Antibodies can also activate the classical complement pathway to derive complement dependent cytotoxicity. 
engagement with these innate cell subsets is critical for the development of maximally effective protective and therapeutic strategies.

Recent results from the AMP study, in which patients were passively transferred with VRC01 to prevent HIV acquisition, has shown that transmission risk is increased as antibody concentrations fall (17) (ClinicalTrials.gov: HVTN 703/HPTN 081). To overcome the short-lived nature of passive transfer, we and others have described recombinant adeno-associated viruses (rAAVs) as a delivery modality, termed Vectored ImmunoProphylaxis (VIP), that utilizes a single intramuscular administration to yield sustained expression of a given antibody (18). To maximize packaging capacity and minimize any potential toxicity, all viral sequences are removed with the exception of two 145 base pair inverted terminal repeats. These innovations allow for a full-length antibody sequence to be successfully packaged and efficiently expressed in animal models $(19,20)$.

Humanized mice are a valuable model in which to test both prophylactic and therapeutic interventions for HIV. These mice are the product of genetic engineering to express human genes or xenografting of immunocompromised mice with stem human cells and tissues. Humanized mouse models have shown longlasting expression of various HIV-1 bNAbs delivered through VIP resulting in protection from viral challenge $(21,22)$. Given the pre-clinical success of vectored antibody strategies, a clinical trial testing the safety and efficacy of bNAb delivery using VIP is currently underway with recent results showing up to microgram per $\mathrm{mL}$ concentrations in circulation which were sustained for at least 18 months post-administration. In this review, we discuss the role of Fc-mediated effector functions during antibodymediated protection from HIV particularly at low concentrations and the potential for vectored immunoprophylaxis to harness effector functions to yield durable protection through sustained bNAb delivery.

\section{PROTECTION FROM HIV ACQUISITION BY BROADLY NEUTRALIZING ANTIBODIES}

The first-generation of HIV-1 broadly neutralizing antibodies including b6, 4E10, 2F5, and b12 were described over twenty years ago and showed limited breadth or potency (23-26). Since then, several second generation bNAbs such as PGDM1400, VRC01, and PGT121 have been characterized with far greater potency and breadth (27). BNAbs target distinct sites of vulnerability on the viral envelope; these include the CD4binding site (CD4bs), the V1V2 loops (V1V2), the V3 loop (V3), the membrane-proximal external region (MPER), and more recently the gp120-41 interface or fusion peptide (2831). Studies in non-human primates (NHPs) have investigated bNAb-mediated protection from SHIV acquisition using various bNAbs targeting each of these sites, including b12 (13), VRC01 (11, 32), 3BNC117 (CD4bs) (9, 33), PGDM1400, CAP256VRC26.25 (V1V2) (10), 10-1074 (34) and PGT121 (V3) (9, 35). A recent meta-analysis of passive immunization studies performed by Pegu et al. (32) measured the rates of SHIV infection after a single administration of a given antibody (32). Collectively, these studies showed that antibody serum concentration against the challenge virus was strongly correlated with protection and that antibody inhibitory concentration required to reduce viral infectivity by fifty or eighty percent $\left(\mathrm{IC}_{50}\right.$ and $\mathrm{IC}_{80}$, respectively) were also strong predictors of protection. Other work has shown that the protective concentration of an antibody in vivo is often 50-200 times greater than the in vitro $\mathrm{IC}_{50}$ value calculated in an in vitro neutralization assay suggesting that the more potent an antibody is, the lower the concentration required to protect (36). Collectively, this work shows that antibody concentration and potency are crucial factors that contribute to protection. However, antibodies are also capable of mediating nonneutralizing effector functions that have been shown to contribute to protection and driving viral clearance $(12,13,16$, $37,38)$.

\section{CONTRIBUTION OF FC-MEDIATED EFFECTOR FUNCTIONS IN HIV PREVENTION AND VIRAL CLEARANCE}

Innate immune cells such as natural killer cells, monocytes, macrophage and neutrophils express a variety of activating and inhibitory Fc-gamma receptors (FcyRs) which can engage with the Fc-region of antibodies to drive $\mathrm{Fc}$-mediated effector functions (39-41). Four different subclasses of Fc receptors have been defined, including three activating receptors Fc $\gamma \mathrm{RI}$, FcyRII and Fc $\gamma$ RIIIa, as well as the inhibitory receptor Fc $\gamma$ RIIb. These molecules drive antibody-dependent innate functions including ADCC, ADCP, ADCD. ADCC occurs when NK and other innate cells form immunological synapses with a target cell through FcyRIIIa engagement to release perforin and granzyme $B$. These cytotoxic granules create pores in the membrane of the target cell, causing it to lyse and die (42-44). Phagocytosis is mediated by monocytes, macrophages, and neutrophils, where immune complex-opsonized cells are engulfed by mononuclear phagocytes through engagement of Fc $\gamma$ RIa and FcyRIIa. Crosslinking of these Fc $\gamma$ Rs leads to downstream degradation of these engulfed target cells (45). Additionally, antibodies can also engage the complement system to drive ADCD. Antibodies bound to envelopes expressed by infected cells can form stable hexameric immune complexes that can recruit complement (45). Antibody-mediated complement activation occurs through the classical pathway in which $\mathrm{Clq}$ is recruited to antibody-immune complexes (46). This results in the formation of a membrane attack complex (MAC) that leads to lysis of the target cell (47).

The role of Fc-mediated effector functions in HIV prevention in patients has been suggested by the analysis of the partially successful RV144 vaccine trial in Thailand, in which patients were administered a heterologous prime-boost vaccine regimen (48). Analysis of uninfected participants showed that antibodies capable of driving Fc-mediated effector functions were positively associated with protection (14). Two antibody-dependent innate 
functions that were strong correlates of decreased risk were ADCC and ADCP (49-51). Interestingly non-neutralizing IgG1 and IgG3 subclass antibodies targeting the V1V2 site mediated these effector functions, raising the possibility that there may be an optimal envelope epitopes to target to best drive these Fc functions. Bradley et al. performed a similar study to that of the RV144 trial in non-human primates, however they designed a vaccine cocktail of various gp120s to increase the diversity of antigen seen by the immune system in the hopes of eliciting broadly neutralizing antibodies (52). Analysis of the elicited antibodies also found that ADCC by NK cells was a major correlate of protection in the monkeys. More recent studies investigating the correlates of protection in a phase $1 \mathrm{~B}$ trial attempting to replicate the RV144 regimen in South Africa (HVTN 097) found that innate immune pathways were highly upregulated, including signatures of ADCC and ADCP however it failed to demonstrate significant protection (53). Collectively, these findings suggest antibodies capable of driving Fc-mediated effector functions may hold promise in future interventions designed to prevent HIV transmission.

In addition to HIV prevention, polyfunctional antibodies have also been found to be associated with HIV control (54). Similar to findings described in RV144 subjects, elite controllers, who maintain low viral loads in the absence of therapy, harbor higher levels of IgG1 and IgG3 antibodies capable of mediating ADCC and ADCP. Antibodies isolated from elite controllers, viremic controllers, infected patients on ART, and infected patients off ART were compared for polyfunctionality and breakdown of IgG isotype. Interestingly, antibodies from elite controllers did not have enhanced polyfunctionality compared to other groups, but there was a higher prevalence of IgG1 and IgG3 subclasses seen in these patients. These antibodies were also able to mediate $\mathrm{ADCC}, \mathrm{ADCP}, \mathrm{ADCD}$, and antibody-dependent neutrophil phagocytosis (ADNP) at lower serum titers compared to the other groups (54). Additionally, patients harboring antibodies that could mediate ADCC were also more likely to develop antibodies that could drive phagocytosis by both monocytes and neutrophils. Collectively, this data suggests that polyfunctional antibodies may have a significant impact on viral clearance in chronically infected individuals.

Understanding the role effector functions play in both prevention and control in chronic infection has largely focused on non-neutralizing antibodies elicited by patients. Although the vaccine regimen administered in the RV144 trial showed promising results, when an analogous regimen was given in South Africa in the HVTN02 trial it failed to achieve statistically significant protection, demonstrating the need for continued development of alternative strategies. Additionally, a study by Dugast et al. (55) demonstrated that passive transfer of ADCCinducing non-neutralizing antibodies isolated from elite controllers failed to protect rhesus monkeys from SHIV challenge, suggesting that Fc-mediated effector functions alone are insufficient to protect against viral acquisition (55). In another study, Burton et al. (56) showed that rhesus macaques had limited protection against mucosal SHIV challenge when administered weakly or non-neutralizing antibodies compared to monkeys given a potent bNAb (56). Given these findings, highly potent neutralizing antibodies appear to afford better protection than polyfunctional non-neutralizing antibodies in HIV prevention. However, understanding the capacity for bNAbs to elicit these Fc-mediated effector functions has been of considerable interest as a potential way to harness the polyfunctionality of these antibodies. Additionally, given the promise shown by bNAbs in prevention, there has also been a push to investigate how these antibodies may be employed therapeutically.

A number of groups have independently performed assays designed to measure the protective and therapeutic efficacy of bNAbs across a wide-range of animal models (Table 1). Seminal work in this area by Hessell et al. demonstrated the importance of Fc-mediated effector functions of bNAbs in SHIV prevention. Variants of b12, a first-generation CD4bs bNAb, designed to abrogate Fc-interaction and engagement with Fc $\gamma$ Rs, were passively transferred into rhesus macaques to evaluate the contribution of $\mathrm{Fc}$ effector functions against SHIV challenge (13). Interestingly, NHPs that were given b12-LALA, an Fc variant in which mutations were engineered into the $\mathrm{Fc}$ region to diminish engagement with FcyRs and abrogate ADCD, ADCC, ADCP, and ADNP, were more susceptible to infection compared to macaques that were administered wildtype antibody. However, recent work by Hangartner et al. (60) performing a similar study with PGT121 found differing results (60). Demonstrating no difference in protection among NHPs given PGT121-WT and PGT121-LALA or PGT121LALAPG, a variant that further reduces engagement with

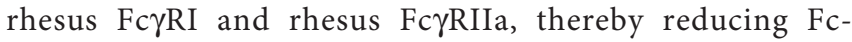
mediated function. Another recent study found similar results also comparing PGT121 and PGT121-LALA to measure protection afforded by $\mathrm{Fc}$ effector function in pigtail marques, finding that the neutralization potency of this bNAb renders Fc effector functions partially redundant (61). It may be more difficult to ascertain the role Fc-mediated effector functions play in protection with a highly potent bNAb, such as PGT121, compared to bNAbs that may be less potent, such as b12 where there may be a more clear distinction in the contribution of effector function (61). Given the results of these studies, it is possible that the protective efficacy of some bNAbs do not benefit from Fc-effector functions. As such, additional work will be needed to fully define the protective properties of Fc-mediated functions.

In addition to prevention, Fc-mediated effector functions of bNAbs have also been investigated in the context of driving viral clearance of established HIV infection. Recently, Asokan et al. measured the contribution of bNAb-mediated effector function in chronically infected rhesus macaques. SHIV-infected monkeys were treated with a CD4bs-directed bNAb, VRC07-LS, or variants harboring $\mathrm{Fc}$ mutations that either enhanced or diminished engagement with FcyRs. Using this panel of mutant antibodies, they determined that innate effector functions, such as ADCC, ADCP and complement fixation contributed approximately $21 \%$ of the observed rate of viral clearance (16). Interestingly, this study did find that VRC07-LS 
TABLE 1 | Protective and therapeutic efficacy of bNAbs in vivo.

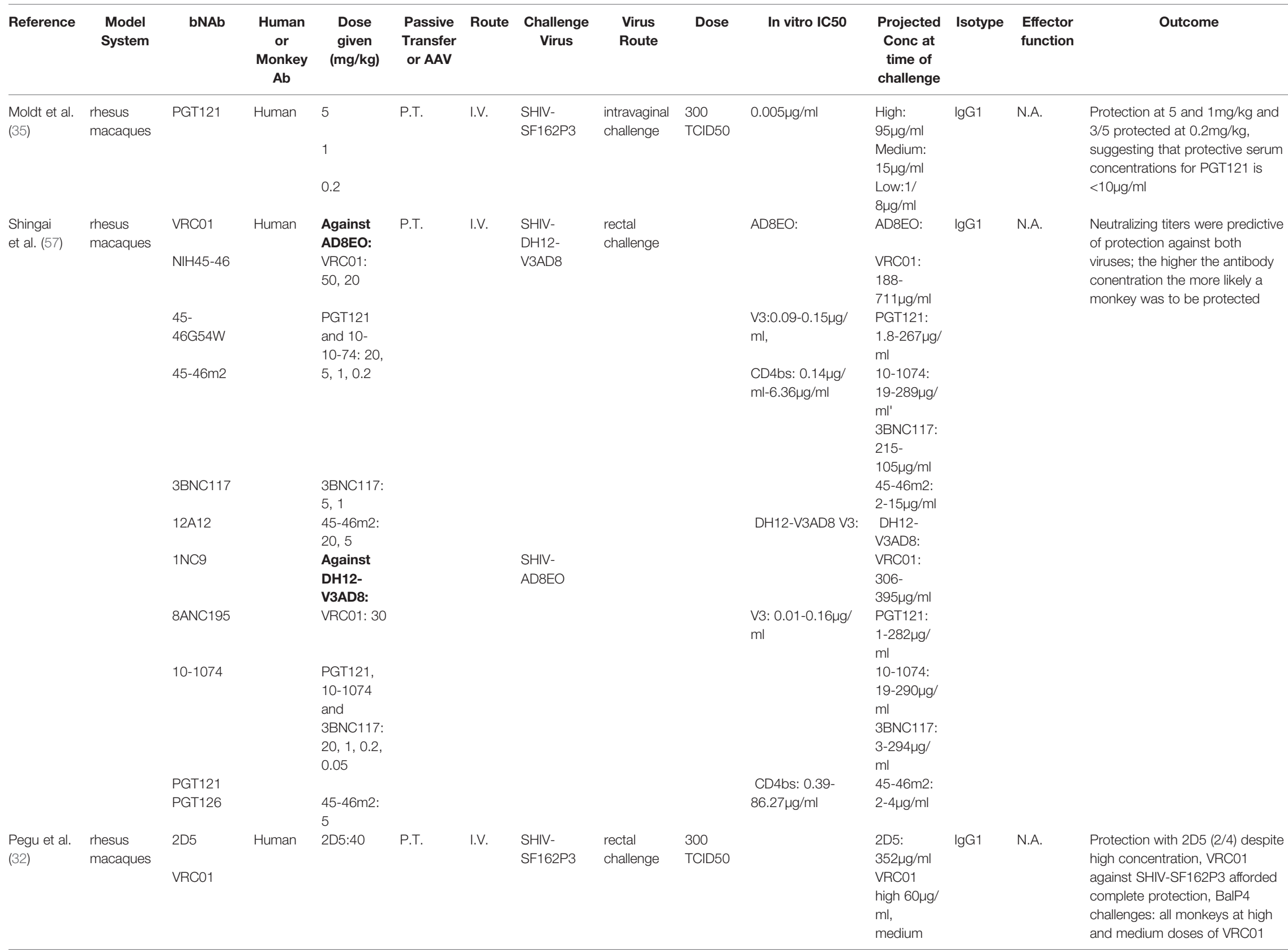




\begin{tabular}{|c|c|c|c|c|c|c|c|c|c|c|c|c|c|c|}
\hline Reference & $\begin{array}{l}\text { Model } \\
\text { System }\end{array}$ & bNAb & $\begin{array}{c}\text { Human } \\
\text { or } \\
\text { Monkey } \\
\text { Ab }\end{array}$ & $\begin{array}{l}\text { Dose } \\
\text { given } \\
\text { (mg/kg) }\end{array}$ & $\begin{array}{l}\text { Passive } \\
\text { Transfer } \\
\text { or AAV }\end{array}$ & Route & $\begin{array}{c}\text { Challenge } \\
\text { Virus }\end{array}$ & $\begin{array}{l}\text { Virus } \\
\text { Route }\end{array}$ & Dose & In vitro IC50 & $\begin{array}{c}\text { Projected } \\
\text { Conc at } \\
\text { time of } \\
\text { challenge }\end{array}$ & Isotype & $\begin{array}{l}\text { Effector } \\
\text { function }\end{array}$ & Outcome \\
\hline & & PG9 & & $\begin{array}{l}\text { VRC01, } \\
\text { 10E8, } \\
\text { PG9: 20, } \\
5,0.3\end{array}$ & & & BALP4 & & & & $\begin{array}{l}22 \mu \mathrm{g} / \mathrm{ml} \text {, } \\
\text { low } \\
1.31 \mu \mathrm{g} / \mathrm{ml} \\
10 \mathrm{E} 8 \mathrm{high} \\
133 \mu \mathrm{g} / \mathrm{ml}, \\
\mathrm{medium} \\
31 \mu \mathrm{g} / \mathrm{ml} \text {, } \\
\mathrm{low} 1.8 \mu \mathrm{g} / \\
\mathrm{ml} \\
\text { PG9 high } \\
32 \mu \mathrm{g} / \mathrm{ml}, \\
\mathrm{medium} \\
3.7 \mu \mathrm{g} / \mathrm{ml}, \\
\mathrm{low} \\
0.28 \mu \mathrm{g} / \mathrm{ml}\end{array}$ & & & $\begin{array}{l}\text { were protected, at low dose (4/ } \\
\text { 10), } 10 \text { E8 protected all monkeys } \\
\text { at high and medium doses, at } \\
\text { low dose (3/6), PG9 protected (4/ } \\
6 \text { ) at high dose, (3/6) at medium } \\
\text { and no moneys at low dose }\end{array}$ \\
\hline $\begin{array}{l}\text { Julg et al. } \\
\text { (10) }\end{array}$ & $\begin{array}{l}\text { rhesus } \\
\text { macaques }\end{array}$ & $\begin{array}{l}\text { PGDM1400 } \\
\text { CAP256- } \\
\text { VRC26.25- } \\
\text { LS }\end{array}$ & Human & $\begin{array}{l}2 \\
0.4 \\
0.08\end{array}$ & P.T. & I.V. & SHIV-325c & $\begin{array}{l}\text { rectal } \\
\text { challenge }\end{array}$ & $\begin{array}{l}500 \\
\text { TCID50 }\end{array}$ & $\begin{array}{l}\text { PGDM1400=0.037 } \\
\text { CAP256- } \\
\text { VRC26.25=0.003 }\end{array}$ & $\begin{array}{l}\sim 0.1-10 \mu \mathrm{g} / \\
\mathrm{ml}\end{array}$ & $\lg G 1$ & N.A. & $\begin{array}{l}\text { CAP256.VRC26 protection at } \\
\text { high dose (3/3), medium (3/3), } \\
\text { low (3/3), PGMD1400 protection } \\
\text { at high dose }(4 / 5) \text {, medium }(5 / 5 / \text {, } \\
\text { low }(1 / 3)\end{array}$ \\
\hline $\begin{array}{l}\text { Balazs } \\
\text { et al. (18) }\end{array}$ & $\begin{array}{l}\text { Hu-PBMC } \\
\text { mice }\end{array}$ & $\begin{array}{l}\text { 2G12 } \\
\text { b12 } \\
\text { 2F5 } \\
\text { 4E10 } \\
\text { VRC01 }\end{array}$ & Human & N.A. & AAV & I.V. & NL4-3 & I.P. and I.V. & $\begin{array}{l}\text { 1ng p24 } \\
\text { 10ng } \\
\text { p24 }\end{array}$ & & 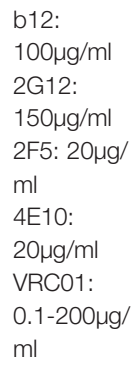 & $\lg G 1$ & N.A. & $\begin{array}{l}\text { Mice given b12 were completely } \\
\text { protected, mice given 2G12, 2F5 } \\
\text { and } 4 \mathrm{E} 10 \text { were partially } \\
\text { protected. Mice expressing } \\
\text { varying doses of VRC01 showed } \\
\text { partial protection: Mice } \\
\text { expressing less than } 10 \mu \mathrm{g} / \mathrm{ml} \\
\text { succumbed to infection but mice } \\
\text { expressing }>10 \mu \mathrm{g} / \mathrm{ml} \text { were } \\
\text { protected }\end{array}$ \\
\hline $\begin{array}{l}\text { Balazs } \\
\text { et al. (21) }\end{array}$ & $\begin{array}{l}\text { BLT } \\
\text { humanized } \\
\text { mice }\end{array}$ & $\begin{array}{l}\text { b12 } \\
\text { VRC01 } \\
\text { VRC07W }\end{array}$ & Human & N.A. & AAV & I.V. & $\begin{array}{l}\text { REJO.c } \\
\text { JR-CSF }\end{array}$ & $\begin{array}{l}\text { intravaginal } \\
\text { challenge }\end{array}$ & $\begin{array}{l}16 n g \\
\text { p24 } \\
\text { REJO.c } \\
50 n g \\
\text { p24 JR- } \\
\text { CSF }\end{array}$ & & $\begin{array}{l}\text { b12: 100- } \\
\text { 300 } \mathrm{\mu g} / \mathrm{ml} \\
\text { VRC01: } \\
\sim 100- \\
300 \mu \mathrm{g} / \mathrm{ml} \\
\text { VRC07W: } \\
\sim 100 \mu \mathrm{\mu g} / \mathrm{ml}\end{array}$ & $\lg G 1$ & N.A. & $\begin{array}{l}\text { bNAbs can maintain long lasting } \\
\text { expression using VIP, can also } \\
\text { reach high concentrations that } \\
\text { are protective against repeated } \\
\text { mucosal challenge }\end{array}$ \\
\hline $\begin{array}{l}\text { Moldt et al. } \\
\text { (58) }\end{array}$ & $\begin{array}{l}\text { rhesus } \\
\text { macaques }\end{array}$ & PGT126 & Human & $\begin{array}{l}10 \\
0.4\end{array}$ & P.T. & I.V. & $\begin{array}{l}\text { SHIV- } \\
\text { SF162P3 }\end{array}$ & $\begin{array}{l}\text { intravaginal } \\
\text { and rectal }\end{array}$ & unknown & $0.3 \mu \mathrm{g} / \mathrm{ml}$ & $\begin{array}{l}10 \mathrm{mg} / \mathrm{kg}: \\
100- \\
125 \mu \mathrm{g} / \mathrm{ml} \\
2 \mathrm{mg} / \\
\mathrm{kg}: 25 \mu \mathrm{g} / \mathrm{ml}\end{array}$ & $\lg G 1$ & N.A. & $\begin{array}{l}\text { No difference in protection } \\
\text { between either route of } \\
\text { challenge, suggesting that there } \\
\text { is similar effiacy of bNAb } \\
\text { proteection against both primary } \\
\text { transmission routes }\end{array}$ \\
\hline
\end{tabular}




\begin{tabular}{|c|c|c|c|c|c|c|c|c|c|c|c|c|c|c|}
\hline Reference & $\begin{array}{l}\text { Model } \\
\text { System }\end{array}$ & bNAb & $\begin{array}{c}\text { Human } \\
\text { or } \\
\text { Monkey } \\
\text { Ab }\end{array}$ & $\begin{array}{l}\text { Dose } \\
\text { given } \\
\text { (mg/kg) }\end{array}$ & $\begin{array}{l}\text { Passive } \\
\text { Transfer } \\
\text { or AAV }\end{array}$ & Route & $\begin{array}{l}\text { Challenge } \\
\text { Virus }\end{array}$ & $\begin{array}{l}\text { Virus } \\
\text { Route }\end{array}$ & Dose & In vitro IC50 & $\begin{array}{c}\text { Projected } \\
\text { Conc at } \\
\text { time of } \\
\text { challenge }\end{array}$ & Isotype & $\begin{array}{l}\text { Effector } \\
\text { function }\end{array}$ & Outcome \\
\hline & & & & & & & & & & & $\begin{array}{l}0.4 \mathrm{mg} / \mathrm{kg}: \\
4 \mu \mathrm{g} / \mathrm{ml}\end{array}$ & & & \\
\hline $\begin{array}{l}\text { Rudicell } \\
\text { et al. (59) }\end{array}$ & $\begin{array}{l}\text { rhesus } \\
\text { macaques }\end{array}$ & $\begin{array}{l}\text { VRC01-LS } \\
\text { VRC07- } \\
\text { 523-LS }\end{array}$ & Human & $\begin{array}{l}0.3 \\
0.2 \\
0.05\end{array}$ & P.T. & I.V. & SHIV-BalP4 & $\begin{array}{l}\text { rectal } \\
\text { challenge }\end{array}$ & $\begin{array}{r}12,800 \\
\text { TCID50 }\end{array}$ & $\begin{array}{l}\text { VRC01-LS: } \\
0.028 \mu \mathrm{g} / \mathrm{ml} \\
\text { VRC07-523-LS: } \\
0.005 \mu \mathrm{g} / \mathrm{ml}\end{array}$ & $\begin{array}{l}\text { VRC01-LS: } \\
2.5 \mu \mathrm{g} / \mathrm{ml} \\
\text { VRC07- } \\
523-\mathrm{LS}: \\
0.47 \mu \mathrm{g} / \mathrm{ml}\end{array}$ & $\lg G 1$ & N.A. & $\begin{array}{l}\text { VRC07-523-LS afforded better } \\
\text { protection compared to VRC01- } \\
\text { LS, suggesting that a more } \\
\text { potent antibody can protect at } \\
\text { these lower concentrations }\end{array}$ \\
\hline $\begin{array}{l}\text { Saunders } \\
\text { et al. (11) }\end{array}$ & $\begin{array}{l}\text { rhesus } \\
\text { macaques }\end{array}$ & $\begin{array}{l}\text { VRC01 } \\
\text { VRC01-LS }\end{array}$ & Simian & 5 & P.T. & I.V. & SHIV-BalP4 & $\begin{array}{l}\text { rectal } \\
\text { challenge }\end{array}$ & unknown & $0.019 \mu \mathrm{g} / \mathrm{ml}$ & $\begin{array}{l}\text { VRC01: } \\
0.1-1 \mu \mathrm{g} / \mathrm{ml} \\
\text { VRC01-LS: } \\
2-6 \mu \mathrm{g} / \mathrm{ml}\end{array}$ & $\lg G 1$ & N.A. & $\begin{array}{l}\text { Introducing an LS mutation into } \\
\text { the antibody led to elevated } \\
\text { antibody levels for a longer } \\
\text { period of time and protected } \\
\text { against mucosal challenge for up } \\
\text { to two months after last antibody } \\
\text { administration }\end{array}$ \\
\hline $\begin{array}{l}\text { Ko et al. } \\
\text { (59) }\end{array}$ & $\begin{array}{l}\text { rhesus } \\
\text { macaques }\end{array}$ & $\begin{array}{l}\text { VRC01, } \\
\text { VRC01-LS } \\
\text { VRC01-LS }\end{array}$ & Human & 0.3 & P.T. & I.V. & SHIV-BalP4 & $\begin{array}{l}\text { rectal } \\
\text { challenge }\end{array}$ & unknown & unknown & $\begin{array}{l}\sim 20- \\
100 \mu \mathrm{g} / \mathrm{ml}\end{array}$ & $\lg G 1$ & $\begin{array}{l}\text { FcRn and } \\
\text { FcyRllla } \\
\text { binding, } \\
\text { ADCC }\end{array}$ & $\begin{array}{l}\text { VRC01-LS affords better } \\
\text { protection against viral challenge } \\
\text { than VRC01, due to its enhanced } \\
\text { binding with FCRn. No detectable } \\
\text { difference in the ability to bind } \\
\text { FCRIlla, suggesting that ADCC is } \\
\text { intact }\end{array}$ \\
\hline $\begin{array}{l}\text { Hessell } \\
\text { et al. (13) }\end{array}$ & $\begin{array}{l}\text { rhesus } \\
\text { macaques }\end{array}$ & $\begin{array}{l}\text { b12-WT } \\
\text { b12-LALA }\end{array}$ & Human & 1 & P.T. & I.V. & $\begin{array}{l}\text { SHIV- } \\
\text { SF162P3 }\end{array}$ & $\begin{array}{l}\text { intravaginal } \\
\text { challenge }\end{array}$ & $\begin{array}{l}\text { TCID50 } \\
10\end{array}$ & $0.18 \mu \mathrm{g} / \mathrm{ml}$ & $\begin{array}{l}\text { b12: 45- } \\
\text { 70 } \mu \mathrm{g} / \mathrm{ml} \\
\text { b12-LALA: } \\
\sim 5-55 \mu \mathrm{g} / \\
\mathrm{ml}\end{array}$ & $\lg G 1$ & $\begin{array}{l}\text { b12-WT } \\
\text { can } \\
\text { mediate } \\
\text { effector } \\
\text { functions, } \\
\text { LALA } \\
\text { variant } \\
\text { cannot } \\
\text { mediate } \\
\text { any } \\
\text { function }\end{array}$ & $\begin{array}{l}\text { Two-fold difference in hazard } \\
\text { ratio between WT and LALA } \\
\text { variant number of challenges to } \\
\text { infection, effector function } \\
\text { appears to play a role in this } \\
\text { difference in protection }\end{array}$ \\
\hline $\begin{array}{l}\text { Hessell } \\
\text { et al. (38) }\end{array}$ & $\begin{array}{l}\text { rhesus } \\
\text { macaques }\end{array}$ & $\begin{array}{l}\text { b12-WT } \\
\text { b12-LALA } \\
\text { b12-KA }\end{array}$ & Human & 25 & P.T. & I.V. & $\begin{array}{l}\text { SHIV- } \\
\text { SF162P3 }\end{array}$ & $\begin{array}{l}\text { intravaginal } \\
\text { challenge }\end{array}$ & $\begin{array}{l}300 \\
\text { TCID50 }\end{array}$ & unknown & $\begin{array}{l}\text { b12-WT: } \\
562 \mu \mathrm{g} / \mathrm{ml} \\
\text { b12-KA: } \\
616 \mu \mathrm{g} / \mathrm{ml} \\
\text { b12-LALA: } \\
534 \mu \mathrm{g} / \mathrm{ml}\end{array}$ & $\lg \mathrm{G} 1$ & $\begin{array}{l}\text { C1q and } \\
\text { FcyR } \\
\text { binding }\end{array}$ & $\begin{array}{l}\text { No difference in protection } \\
\text { between b12-WT and b12-KA ( } 8 / \\
9 \text { protected), but monkeys given } \\
\text { b12-LALA were less protected } \\
(5 / 9)\end{array}$ \\
\hline $\begin{array}{l}\text { Bournazos } \\
\text { et al. (37) }\end{array}$ & $\begin{array}{l}\text { Luciferase } \\
\text { reporter } \\
\text { mice } \\
\text { transduced } \\
\text { with AdV } \\
\text { hCCR5-A2- } \\
\text { hCD4 }\end{array}$ & $\begin{array}{l}\text { 3BNC117 } \\
\text { Jan-74 } \\
\text { 3BCN60 } \\
\text { Jan-79 } \\
\text { 3BC176 } \\
\text { PGT121 } \\
\text { PG16 }\end{array}$ & $\begin{array}{l}\text { mouse- } \\
\text { human } \\
\text { chimeric } \\
\text { (human } \\
\text { bNAbs } \\
\text { with } \\
\text { mouse }\end{array}$ & $200 \mu \mathrm{g}$ & P.T. & S.C. & $\begin{array}{l}\text { HIV-YU-2 } \\
\text { Cre } \\
\text { pseudovirus }\end{array}$ & I.V. & unknown & $\begin{array}{l}\text { 3BNC117: } 0.021 \\
\text { 1-74: >50 } \\
\text { 3BNC60: } 0.018 \\
\text { 1-79: } 24.8 \\
\text { 3BNC176: } 1.278 \\
\text { PGT121: } 0.44 \\
\text { PG16: } 0.8\end{array}$ & unknown & $\begin{array}{l}\text { mlgG2a } \\
\text { and } \\
\text { mlgG1 } \\
\text { D265A }\end{array}$ & $\begin{array}{l}\text { FcyR } \\
\text { binding as } \\
\text { a } \\
\text { surrogate } \\
\text { for Fc } \\
\text { effector } \\
\text { function }\end{array}$ & $\begin{array}{l}\text { mlgG1 and mlgG1 D265A (Fc- } \\
\text { null) variants of bNAbs had higher } \\
\text { rates of infection compared to } \\
\text { mlgG2a (intact Fc function) } \\
\text { variants of all bNAbs, suggesting } \\
\text { that Fc-mediated effector } \\
\text { functions play a role in protection }\end{array}$ \\
\hline
\end{tabular}


TABLE 1 | Continued

\begin{tabular}{|c|c|c|c|c|c|c|c|c|c|c|c|c|c|c|}
\hline Reference & $\begin{array}{l}\text { Model } \\
\text { System }\end{array}$ & bNAb & $\begin{array}{c}\text { Human } \\
\text { or } \\
\text { Monkey } \\
\text { Ab }\end{array}$ & $\begin{array}{l}\text { Dose } \\
\text { given } \\
\text { (mg/kg) }\end{array}$ & $\begin{array}{l}\text { Passive } \\
\text { Transfer } \\
\text { or AAV }\end{array}$ & Route & $\begin{array}{c}\text { Challenge } \\
\text { Virus }\end{array}$ & $\begin{array}{l}\text { Virus } \\
\text { Route }\end{array}$ & Dose & In vitro IC50 & $\begin{array}{l}\text { Projected } \\
\text { Conc at } \\
\text { time of } \\
\text { challenge }\end{array}$ & Isotype & $\begin{array}{l}\text { Effector } \\
\text { function }\end{array}$ & Outcome \\
\hline & & & $\begin{array}{l}\text { constant } \\
\text { region } \\
\text { heavy } \\
\text { chains) }\end{array}$ & & & & & & & & & & & \\
\hline $\begin{array}{l}\text { Bournazos } \\
\text { et al. (37) }\end{array}$ & $\begin{array}{l}\text { NRG } \\
\text { humanized } \\
\text { mice }\end{array}$ & $\begin{array}{l}\text { 3BNC117- } \\
\text { WT } \\
\text { 3BNC117- } \\
\text { GRLR } \\
\text { 3BNC117- } \\
\text { GASDALIE }\end{array}$ & Human & $\begin{array}{l}100 \mu \mathrm{g} / \mathrm{ml} \\
\text { (high dose) } \\
20 \mu \mathrm{g} / \mathrm{ml} \\
\text { (low dose) }\end{array}$ & P.T. & S.C. & HIV-YU-2 & I.V. & $\begin{array}{l}57.5 n g \\
\text { p24 }\end{array}$ & $0.021 \mu \mathrm{g} / \mathrm{ml}$ & $>10 \mu \mathrm{g} / \mathrm{ml}$ & $\lg G 1$ & $\begin{array}{l}\text { FcyR } \\
\text { binding as } \\
\text { a } \\
\text { surrogate } \\
\text { for Fc } \\
\text { effector } \\
\text { function }\end{array}$ & $\begin{array}{l}\text { Mice given 3BNC117-GASDALIE } \\
\text { (Fc enahncing) exhibited lower } \\
\text { rates of infection compared to } \\
\text { WT and 3BNC117-GRLR (FC- } \\
\text { null) }\end{array}$ \\
\hline $\begin{array}{l}\text { Julg et al. } \\
\text { (10) }\end{array}$ & $\begin{array}{l}\text { rhesus } \\
\text { macaques }\end{array}$ & $\begin{array}{l}\text { 3BNC117, } \\
\text { PGT121 }\end{array}$ & Human & 10 & P.T. & I.V. & SHIV-327c & $\begin{array}{l}\text { rectal } \\
\text { challenge }\end{array}$ & $\begin{array}{l}300 \\
\text { TCID50 }\end{array}$ & 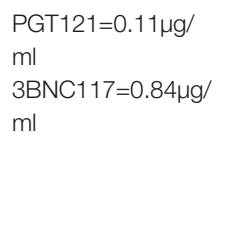 & $\begin{array}{l}\sim 50- \\
150 \mu \mathrm{g} / \mathrm{ml}\end{array}$ & $\lg G 1$ & $\begin{array}{l}\mathrm{ADCP} \\
\text { and } \mathrm{CDC}\end{array}$ & $\begin{array}{l}\text { PGT121 protected monkeys at } \\
\text { both doses (high dose } 4 / 4 \text {, low } \\
\text { dose } 2 / 2 \text { ), } 3 \text { BNC } 117 \text { did not } \\
\text { protect at low dose (0/3) and } \\
\text { only protect } 1 / 4 \text { monkeys at high } \\
\text { dose, no dfference in mediating } \\
\text { effector function }\end{array}$ \\
\hline $\begin{array}{l}\text { Hangartner } \\
\text { et al. (60) }\end{array}$ & $\begin{array}{l}\text { rhesus } \\
\text { macaques }\end{array}$ & $\begin{array}{l}\text { PGT121 } \\
\text { PGT121- } \\
\text { LALA, } \\
\text { PGT121- } \\
\text { LALAPG }\end{array}$ & Human & 1 & P.T. & I.V. & $\begin{array}{l}\text { SHIV- } \\
\text { SF162P3 }\end{array}$ & $\begin{array}{l}\text { intravaginal } \\
\text { challenge }\end{array}$ & $\begin{array}{l}300 \\
\text { TCID50 }\end{array}$ & & 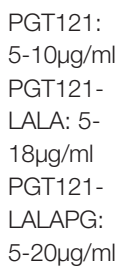 & $\lg G 1$ & $\begin{array}{l}\text { ADCP } \\
\text { and } \\
\text { ADCC }\end{array}$ & $\begin{array}{l}\text { No difference in protection } \\
\text { between PGT121 and PGT121- } \\
\text { LALA, suggesting that effector } \\
\text { function for this antibody maynot } \\
\text { contribute to protection against } \\
\text { this given virus }\end{array}$ \\
\hline
\end{tabular}

N.A., not applicable; S.C., subcutaneous. 
with $\mathrm{Fc}$ mutations to enhance FcyR binding led to NK cell death one hour after bnAb infusion, likely due to FcyRIIIa crosslinking on the cell surface and driving necroptosis, in turn leading to reduced ADCC. It is possible that over-optimization of an antibody may have detrimental effects early on in delivery, and this should be taken into consideration if these antibodies are to be used therapeutically.

Humanized mice have also been an effective model in which to study the role of antibody effector functions $(12,37,62)$. Similar to NHP studies, several groups have investigated the protective effects of various bNAbs and their ability to drive effector functions in the context of both HIV prevention and viral clearance during infection. In one study, humanized NOD Rag1 $^{-1}$ Il2g null (NRG) mice given the CD4-binding site targeting bNAb 3BNC117 and challenged with HIV were found to have enhanced viral clearance 24 hours-post challenge compared to the control mice given a non-specific antibody (37). 3BNC117 has also been used to measure the role of innate immunity in ART treated humanized NRG mice (62). Mutations were introduced into the Fc-region of the antibody to abrogate binding to both murine and human FcyRs. HIV-infected mice taken off ART and given Fc-null (3BNC117-GRLR) antibody exhibited slower viral clearance as compared to mice given the wild-type antibody and similar clearance to control mice given a non-specific antibody. These studies implicate innate cells through $\mathrm{Fc}$ engagment in viral clearance in humanized mice. Other work has also aimed to measure the contribution of Fcmediated viral clearance during early infection (12). In this study, a bi-specific bNAb composed of 3 BNC117 and PGDM1400 was administered to infected mice. Another group of infected mice were given the same bNAb harboring mutations in the Fc-region to prevent $\mathrm{Fc} \gamma \mathrm{R}$ engagement and downstream effector functions. Results showed that innate effector functions contributed $25-31 \%$ of the antiviral activity seen in humanized mice while $75 \%$ was due to antibody neutralization.

Considerable effort has been made to determine whether there are optimal epitopes on the viral envelope that may facilitate these activities. BNAbs targeting each of the major epitopes have been assessed for their ability to mediate innate functions, including ADCC, ADCP, and antibody-dependent complement mediated cell lysis (ADCML) against diverse viruses that span various clades $(63,64)$. Interestingly, while neutralization potency does not appear to predict effector function, there is a weak correlation between antibody binding and effector function $(63,64)$. Other groups have confirmed these findings, showing that neither neutralization potency nor breadth are strong predictors of effector activity (64-68). Instead they have shown that binding avidity is better correlated with function (64-68). As of yet, there is no clear consensus of which target epitope for bNAbs best mediates Fc-driven functions. Instead, it has been suggested that modes of binding by nonneutralizing antibodies can have a dramatic effect on the resulting potency of the downstream effector function such as ADCC (67). Two monoclonal antibodies targeting the $\mathrm{C} 1$ and $\mathrm{C} 4$ gp120 regions with similar antigen affinities exhibit markedly different responses in driving ADCC (67). Interestingly, when crystal structures were determined for each of the antibodies with the corresponding antigen, they showed that antibody orientation on the bound antigen may have enhanced formation of an immune complex, resulting in increased potency of downstream innate immunity (67). The angle of approach for a given bNAb likely affects how these immune complexes can form and engage with FcyRs (67). Additionally, numerous structural studies have elucidated Fc $\gamma \mathrm{R}-\mathrm{Fc}$ interactions to determine the precise mechanism of antibody binding to FcyRs $(40,69-72)$. Antibody-antigen structures have also provided insight on $\mathrm{Fc}$ presentation and angle of antibody binding to an antigen may influence optimal Fc $\gamma \mathrm{R}$ engagement to lead to downstream effector function, such as ADCC (73). There is still much work to be done to understand how modes of antibody engagement can drive effector functions across diverse viral strains and how antibodies function post antigen-binding.

Other avenues of investigation have looked to optimize bNAbs to elicit more potent Fc effector function. One potential approach has been the use of bNAbs expressed as different isotypes that have enhanced effector function, such as IgG3. Recent work by Richardson et al. (74) compared IgG1 and IgG3 variants of V2-specific bNAbs CAP256-VRC26.25 and CAP256VRC29 to measure how isotype contributed to potent Fc effector functions (74). The group was able to isolate these two bNAbs from an HIV-infected individual that had mounted a potent V2specific response and elicited high levels of IgG3 antibodies that significantly contributed to the total effector function activity measured in the serum (74). These two bNAbs, CAP256VRC26.25 and CAP256-VRC29, were constructed as IgG3 variants using different IGHG3 alleles to measure Fc function and neutralization. They also expressed these bNAbs as IgG1 isotypes and found reduced neutralization and $\mathrm{Fc}$ function compared to the IgG3 variants but no difference in antigen binding. They found IgG3 potency was likely due to its longer hinge length than that of IgG1. Therapeutically, however, employing IgG3 in patients may pose a challenge as the affinity for the neonatal receptor $\mathrm{FcRn}$ is drastically reduced compared to IgG1, leading to a far shorter half-life (75). However, recent work demonstrated that alteration of the hinge length of IgG1 and IgG3 bNAbs VRC01 and 447-52D contributed to Fc mediated effector functions (76). To make the IgG1 variants, exons derived from IgG3, including exon a which encodes the upper and core hinge regions, and exons b-d that encode the core hinge repeat sequence were sequentially added, resulting in hinge variants up to 5 times longer than wild-type IgG1. They repeated the same hinge alteration for IgG3, and included the IgG1 hinge length as an additional variant. When measuring phagocytosis by all these variants, they found that a longer hinge length significantly enhanced the Fc effector function, suggesting that the length can lead to a more potent response. In addition, in vivo stability of hinge variants of IgG1 were measured and the rate of plasma decay in mice was similar to that of the wild-type, suggesting that such alterations may be viable approaches to harness $\mathrm{Fc}$ mediated effector function by bNAbs.

In addition to understanding how hinge length, isotype and subclass contribute to optimal Fc effector function, considerable 
effort has identified point mutations in the $\mathrm{Fc}$ region capable of enhancing Fc $\gamma R$ engagement and downstream function (77). In 2001, Shields et al. mapped the binding site of IgG1 for Fc $\gamma$ Rs, including Fc $\gamma$ RII, Fc $\gamma$ RIIIa and FcRn by mutagenesis of an IgG1 antibody. From these variants, specific point mutations in the Fc region of the antibody emerged that could enhance or diminish binding to the FcyRs described above (78). One modification, S298A/E333A/K334A, showed enhanced binding to Fc $\gamma$ RIIIa but decreased binding to FcyRIIa, resulting in improved ADCC response. Further work has elucidated alternative Fc modifications that have led to enhanced Fc $\gamma$ RIIIa binding and ADCC, including S239D/I332E, S329D/A330L/I332E, G236A/ S239D/I332E and F243L/R292P/Y300L/V305I/P396L (79-81). Other Fc modifications have led to increased Fc $\gamma$ RIIa binding and ADCP, including G236A, G236A/A330I/I332E, and G236A/ S239D/A330L/I332E $(80,82)$. Some mutations have led to both enhanced ADCC and ADCP, including S239D/I332E, S239D/ A330L/I332E and G236A/S239D/I332E. In addition to introduction of $\mathrm{FC}$ point mutations, afucosylation of IgG1 antibodies led to dramatically increased ADCC (83). Minimal alterations to antibodies can maximize downstream Fc functionality, and these modifications can be used therapeutically to improve bNAb-mediated protection.

Given the potential for bNAb-mediated protection in HIV prevention and viral clearance, the question of implementation has come to the forefront. The AMP clinical trials utilized passive transfer of VRC01, a CD4bs bNAb, to measure HIV prevention in different populations, including HIV-uninfected men who have sex with men (MSM), transgender men who have sex with men, and sexually active women in sub-Saharan Africa $(17,84-$ 86) ClinicalTrials.gov: NCT02716675 (17, 84-86). The results from these trials have been promising, with excellent safety and tolerability to bNAb administration and reduced transmission of sensitive strains. However, one drawback to passive immunization is the need for constant re-administration in order to maintain steady-state bNAb concentrations. This requirement poses significant challenges to feasibly scale and implement as a widespread prophylaxis. In order to overcome this challenge, other methods of delivery can be employed, such as vector-mediated delivery. Adeno Associated Virus (AAV) based gene replacement therapies have been used to treat a variety of diseases, and recent advances in AAV technology have demonstrated sustained bNAb expression in humans in an ongoing clinical trial.

\section{UTILIZING AAV-DELIVERY OF BROADLY NEUTRALIZING ANTIBODIES}

AAVs are non-enveloped viruses that belong to the Parvoviridae family $(85,86)$. AAVs are unable to replicate on their own, and as such require a helper virus, such as an adenovirus or herpesvirus to productively replicate within cells (87-90). They are composed of an icosahedral protein capsid surrounding a single stranded DNA genome of approximately 4700 base pairs. The natural AAV genome consists of a rep and cap gene flanked by two inverted terminal repeats (ITRs) (91). The rep gene encodes proteins necessary for virion assembly, including Rep78, Rep68, Rep52 and Rep40. The cap gene encodes for three capsid proteins, VP1, VP2 and VP3 and the assembly activating protein (AAP) and membrane-associated accessory protein (MAAP) in alternative reading frames $(87,92-97)$. AAV virions are comprised of $60 \mathrm{VP}$ subunits, and each subunit has nine variable regions that dictate tropism and intracellular trafficking (91). Currently, there are more than 100 AAV serotypes identified that all differ in primary receptor usage and tissue tropism (98). During infection, AAVs bind to receptors on target cells which trigger endocytosis into endosomes from which they escape and traffic to the nucleus. Here, the inverted terminal repeats (ITRs) present on either end of the genome self-prime second strand synthesis, which is the rate-limiting step prior to gene expression (99-102). The ITRs are the only requirement for packaging DNA into the capsid (103) As a consequence, recombinant AAV vectors have approximately $96 \%$ of their genome removed, including all viral coding sequences. This allows for greater packaging capacity and lowers the potential for viral toxicity (91). In place of these coding sequences, a transgene of interest, up to approximately 4,500 base pairs, can be introduced between the ITRs (104). Following transduction, these recombinant viral genomes form head-to-tail concatemers within the nucleus, where they persist as non-integrated episomal genomes (105, 106).

To date, AAV gene therapies have been successful in treating diseases in the therapeutic areas of ophthalmology, neurology, hematology, metabolic and musculoskeletal disorders $(99,107)$. This platform can also be used for delivering biological therapeutics for chronic infectious diseases, such as HIV, through delivery of small molecule inhibitors, immunoadhesins, or HIV broadly neutralizing antibodies. This platform has the benefit of enabling specific gene-encoded antibodies to be delivered, representing a viable approach to incorporating Fc-enhancing mutations to improve innate immune functionality of the delivered protein. In 2002, Lewis et al. demonstrated the use of a dual promoter rAAV vector to express full-length b12 in Rag1 $1^{-/-}$mice (20). Subsequent enhancements were made to the viral vector by Fang et al. improved packaging and cleavage of these antibodies in vivo using a picornavirus $2 \mathrm{~A}$ self-processing peptide in order to express both the heavy and light chains of an antibody from a single open reading frame (19). A furin cleavage site was also introduced between the C-terminus of the heavy chain and $\mathrm{N}$ terminus of the $2 \mathrm{~A}$ sequence to enable removal of remaining $2 \mathrm{~A}$ residues (108). These alterations led to significant improvement in antibody expression, resulting in concentrations well over $1 \mathrm{mg} / \mathrm{ml}$ in serum.

Johnson et al. first demonstrated the efficacy of a selfcomplementary AAV (scAAV) vector that expressed SIVspecific immunoadhesins composed of recombinant antibody fragments (109). They administered one intramuscular injection of this scAAV1 into rhesus macaques, resulting in serum expression of the immunoadhesins four weeks after 
administration. Our lab utilized AAV serotype 8 capsid to express a full-length HIV bNAb in vivo. Enhancements were made to the vector, including designing a novel promoter that combined the CMV enhancer and chicken $\beta$-actin promoter followed by an artificial intron containing the ubiquitin enhancer region (18). These changes led to significantly improved antibody expression which enabled this improved vector system to deliver various HIV bNAbs targeting different viral epitopes and measured protection against repeated HIV mucosal challenge in humanized mice (21). This system has also been used to deliver CAP256-antibodies and CAP228-antibodies in immunocompetent mice, both of which target the V2 loops and have been shown to mediate ADCC (110). NHP studies have also demonstrated expression of a simianized form of VRC07, a CD4bs-directed bNAb, and anti-SIV neutralizing antibodies, ITS01 and ITS06.02 $(111,112)$. As a result of these promising proof-of-concept animal studies, two separate Phase I clinical trials were initiated to test VIP in humans.

In one study, AAV was used to deliver PG9, a V1V2-directed $\mathrm{bNAb}$, chosen for its potent neutralization capacity (ClinicalTrials.gov: NCT01937455) (113). This clinical trial looked at the safety and efficacy of PG9 delivery using an rAAV-1 vector. The PG9 heavy and light chains were codon optimized to increase expression in the rAAV vector. Additionally, a 21-amino acid synthetic signal peptide was included in order to improve secretion into the serum. The transgene consisted of a dual promoter system to independently express the variable heavy and variable light chains of the IgG1 antibody. The heavy chain was expressed under a CMV promoter and the light chain was expressed by the EF1a promoter (Figure 2). Healthy, non-HIV infected, men aged 18-45 were administered rAAV1-PG9DP through intramuscular injection. Results showed that the AAV caused no harmful side effects to the volunteers, and muscle biopsies showed detectable PG9 by RT-PCR as well as IgG within muscle cells and extracellular tissues by immunohistochemistry. However, PG9 was not detectable in the serum by ELISA, although it is important to note that the limit of detection in the assay was $2.5 \mu \mathrm{g} / \mathrm{ml}$. In support of these findings, no HIV neutralizing activity was detectable in the sera. Importantly, they observed anti-drug antibody responses in many of the participants of the study, suggesting that these may have limited the potential for PG9 expression (113).

Independently, a second on-going clinical trial by the NIH is testing the safety and efficacy of VRC07 delivery through an rAAV8 viral vector to HIV-infected adults aged 18-60 (AAV8VRC07; ClinicalTrials.gov: NCT03374202). The vector design used in this study was analogous to those described in previous papers from our laboratory and include the CASI promoter and optimized F2A-containing VRC07 transgene (Figure 2). Recent results from this clinical trial presented at the 2021 Conference on Retroviruses and Opportunistic Infections meeting showed detectable expression of VRC07 antibody as high as $1 \mu \mathrm{g} / \mathrm{mL}$ in circulation, with several patients maintaining VRC07 concentrations well over a year after administration. In contrast to results from the earlier study, VRC07 neutralizing activity was detected in trial participants, suggesting that antibodies produced as a result of VIP retained their activity in vivo. This trial represents the first demonstration of long-lived systemic production of a broadly neutralizing antibody in humans, providing strong evidence for the potential of vectored antibody delivery. Despite this success, some participants developed anti-drug antibodies against the VRC07 antibody variable regions, leading to loss of antibody expression.

A

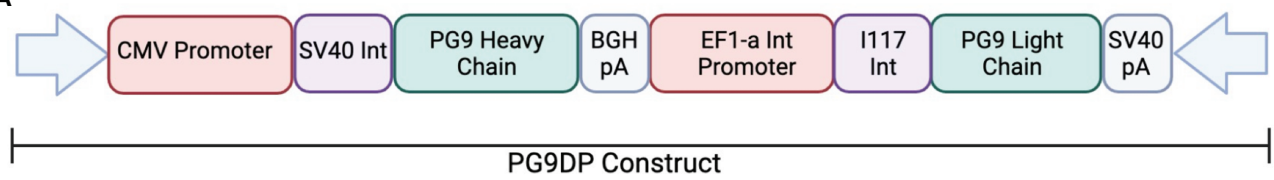

B

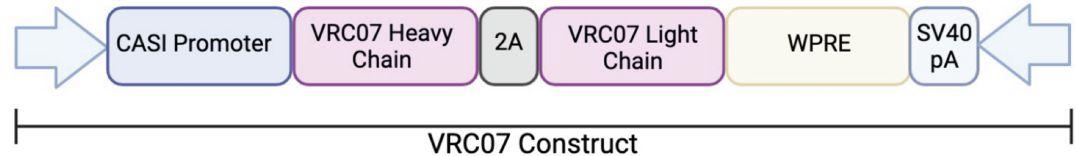

C

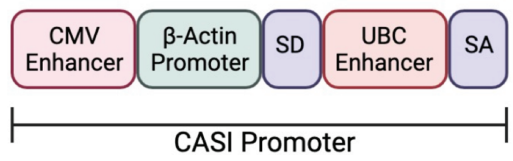

FIGURE 2 | Transgene construct used in clinical trials testing AAV delivery of bNAbs. (A) The dual promotor transgene cassette was used to expressed PG9 in an rAAV-1 vector. The heavy chain is expressed the CMV promoter while the light chain is expressed by the EF1a promoter. (B) The transgene cassette used to express VRC07 in an rAAV-8 vector. Both heavy and light chains are expressed through the CASI promotor shown in (C). 
As such, additional improvements to the AAV transgene may be necessary to enable widespread use of VIP for HIV prevention. Looking forward, this system could be utilized for delivery of optimized bNAbs that contain altered Fc-regions with hinge length changes or even different isotypes to improve Fc $\gamma \mathrm{R}$ binding. The use of such optimized transgenes has the potential to reduce the concentrations of bNAbs necessary to prevent HIV acquisition.

\section{DISCUSSION}

Broadly neutralizing antibodies have been shown to be promising candidates for HIV prevention, therapy and possibly cure. Passive administration of bNAbs have demonstrated that antibody concentration and potency are important parameters correlated with protection against HIV acquisition. Other nonneutralizing functions, including $\mathrm{ADCC}, \mathrm{ADCP}$ and $\mathrm{ADCD}$ have also been shown to be critical in this context. As a result, there is growing interest in understanding whether there are optimal viral epitopes that antibodies can target to effectively elicit protective responses. Early findings from the RV144 vaccine study suggested that non-neutralizing antibodies targeting the V2 site were implicated in preventing disease acquisition. However, when bNAbs targeting different sites of vulnerability were tested for their ability to mediate these same non-neutralizing functions, results were variable and largely dependent upon the challenge virus. Further work is needed to

\section{REFERENCES}

1. Pandey A, Galvani AP. The Global Burden of HIV and Prospects for Control. Lancet HIV. (2019) 6(12):e809-11. doi: 10.1016/S2352-3018(19) 30230-9

2. Morris L, Mkhize NN. Prospects for Passive Immunity to Prevent HIV Infection. PloS Med (2017) 14(11):e1002436. doi: 10.1371/journal.pmed.1002436

3. Martinez-Navio JM, Fuchs SP, Pantry SN, Lauer WA, Duggan NN, Keele BF, et al. Adeno-Associated Virus Delivery of Anti-HIV Monoclonal Antibodies can Drive Long-Term Virologic Suppression. Immunity (2019) 50(3):567-75. doi: 10.1016/j.immuni.2019.02.005

4. Gardner MR. Promise and Progress of an HIV-1 Cure by Adeno-Associated Virus Vector Delivery of Anti-HIV-1 Biologics. Front Cell Infect Microbiol (2020) 10:176. doi: 10.3389/fcimb.2020.00176

5. Gray ES, Madiga MC, Hermanus T, Moore PL, Wibmer CK, Tumba NL, et al. The Neutralization Breadth of HIV-1 Develops Incrementally Over Four Years and Is Associated With CD4+ T Cell Decline and High Viral Load During Acute Infection. J Virol (2011) 85(10):4828-40. doi: 10.1128/ JVI.00198-11

6. Hraber P, Seaman MS, Bailer RT, Mascola JR, Montefiori DC, Korber BT. Prevalence of Broadly Neutralizing Antibody Responses During Chronic HIV-1 Infection. AIDS (2014) 28(2):163-9. doi: 10.1097/QAD. 0000000000000106

7. Klein F, Mouquet H, Dosenovic P, Scheid JF, Scharf L, Nussenzweig MC. Antibodies in HIV-1 Vaccine Development and Therapy. Science (2013) 341 (6151):1199-204. doi: 10.1126/science.1241144

8. Walker LM, Huber M, Doores KJ, Falkowska E, Pejchal R, Julien J-P, et al. Broad Neutralization Coverage of HIV by Multiple Highly Potent Antibodies. Nature (2011) 477(7365):466-70. doi: 10.1038/nature10373

9. Julg B, Sok D, Schmidt SD, Abbink P, Newman RM, Broge T, et al. Protective Efficacy of Broadly Neutralizing Antibodies With Incomplete Neutralization understand if there is an optimal site that can facilitate these functions across a wide range of diverse strains. Additionally, several in vivo studies measured the contribution of these effector functions in protection, but questions remain as to contributions of individual functions, such as ADCC, to mediating protection. Future work could help to identify which effector functions contribute most to bNAb-mediated protection, and armed with this improved understanding, specific Fc mutations or hinge length modifications could be made to the antibody to improve therapeutic outcomes. These are especially relevant in the context of vectored antibody delivery, which represents a promising approach capable of integrating advances made in our understanding of antibody-mediated innate immune function into future clinical products. However, transduction efficiency is relatively low as compared to pre-clinical models and there appears to be a significant proportion of recipients who mount an immune response against the antibody transgene. Future studies will be needed to improve the consistency of antibody delivery using this system, including optimizing the vector to improve antibody concentrations and minimizing anti-drug antibodies elicited in response to existing rAAV vectors.

\section{AUTHOR CONTRIBUTIONS}

$\mathrm{MP}$ and $\mathrm{AB}$ conceived of and wrote the manuscript. All authors contributed to the article and approved the submitted version.

Activity Against Simian-Human Immunodeficiency Virus in Rhesus Monkeys. J Virol (2017) 91(20):e.1187-17. doi: 10.1128/JVI.01187-17

10. Julg B, Tartaglia LJ, Keele BF, Wagh K, Pegu A, Sok D, et al. Broadly Neutralizing Antibodies Targeting the HIV-1 Envelope V2 Apex Confer Protection Against a Clade C SHIV Challenge. Sci Trans Med (2017) 9: eaal1321. doi: 10.1126/scitranslmed.aal1321

11. Saunders KO, Pegu A, Georgiev IS, Zeng M, Joyce MG, Yang Z-Y, et al. Sustained Delivery of a Broadly Neutralizing Antibody in Nonhuman Primates Confers Long-Term Protection Against Simian/Human Immunodeficiency Virus Infection. J Virol (2015) 89(11):5895-903. doi: 10.1128/JVI.00210-15

12. Wang P, Gajjar MR, Yu J, Padte NN, Gettie A, Blanchard JL, et al. Quantifying the Contribution of Fc-Mediated Effector Functions to the Antiviral Activity of Anti-HIV-1 Igg1 Antibodies In Vivo. Proc Natl Acad Sci (2020) 117:18002-9. doi: 10.1073/pnas.2008190117

13. Hessell AJ, Poignard P, Hunter M, Hangartner L, Tehrani DM, Bleeker WK, et al. Effective, Low-Titer Antibody Protection Against Low-Dose Repeated Mucosal SHIV Challenge in Macaques. Nat Med (2009) 15:951-4. doi: $10.1038 / \mathrm{nm} .1974$

14. Liao H-X, Bonsignori M, Munir Alam S, McLellan JS, Tomaras GD, Anthony Moody $\mathrm{M}$, et al. Vaccine Induction of Antibodies Against a Structurally Heterogeneous Site of Immune Pressure Within HIV-1 Envelope Protein Variable Regions 1 and 2. Immunity (2013) 38:176-86. doi: 10.1016/j.immuni.2012.11.011

15. Ackerman ME, Barouch DH, Alter G. Systems Serology for Evaluation of HIV Vaccine Trials. Immunol Rev (2017) 275(1):262-70. doi: 10.1111/ imr. 12503

16. Asokan M, Dias J, Liu C, Maximova A, Ernste K, Pegu A, et al. Fc-Mediated Effector Function Contributes to the In Vivo Antiviral Effect of an HIV Neutralizing Antibody. Proc Natl Acad Sci U S A (2020) 117(31):18754-63. doi: $10.1073 /$ pnas.2008236117 
17. Corey L, Gilbert PB, Juraska M, Montefiori DC, Morris L, Karuna ST, et al. Two Randomized Trials of Neutralizing Antibodies to Prevent HIV-1 Acquisition. N Engl J Med (2021) 384(11):1003-14. doi: 10.1056/ NEJMoa2031738

18. Balazs AB, Chen J, Hong CM, Rao DS, Yang L, Baltimore D. Antibody-Based Protection Against HIV Infection by Vectored Immunoprophylaxis. Nature (2012) 481:81-4. doi: 10.1038/nature10660

19. Fang J, Qian J-J, Yi S, Harding TC, Tu GH, VanRoey M, et al. Stable Antibody Expression at Therapeutic Levels Using the 2A Peptide. Nat Biotechnol (2005) 23(5):584-90. doi: 10.1038/nbt1087

20. Lewis AD, Chen R, Montefiori DC, Johnson PR, Reed Clark K. Generation of Neutralizing Activity Against Human Immunodeficiency Virus Type 1 in Serum by Antibody Gene Transfer. J Virol (2002) 76:8769-75. doi: 10.1128/ jvi.76.17.8769-8775.2002

21. Balazs AB, Ouyang Y, Hong CM, Chen J, Nguyen SM, Rao DS, et al. Vectored Immunoprophylaxis Protects Humanized Mice From Mucosal Hiv Transmission. Nat Med (2014) 20(3):296-300. doi: 10.1038/nm.3471

22. Fuchs SP, Martinez-Navio JM, Piatak MJr, Lifson JD, Gao G, Desrosiers RC. AAV-Delivered Antibody Mediates Significant Protective Effects Against Sivmac239 Challenge in the Absence of Neutralizing Activity. PloS Pathog (2015) 11(8):e1005090. doi: 10.1371/journal.ppat.1005090

23. Burton DR, Barbas CF, Persson MA, Koenig S, Chanock RM, Lerner RA. A Large Array of Human Monoclonal Antibodies to Type 1 Human Immunodeficiency Virus From Combinatorial Libraries of Asymptomatic Seropositive Individuals. Proc Natl Acad Sci (1991) 88:10134-7. doi: 10.1073/pnas.88.22.10134

24. Burton DR, Pyati J, Koduri R, Sharp SJ, Thornton GB, Parren PW, et al. Efficient Neutralization of Primary Isolates of HIV-1 by a Recombinant Human Monoclonal Antibody. Science (1994) 266(5187):1024-7. doi: 10.1126/science. 7973652

25. Purtscher M, Trkola A, Gruber G, Buchacher A, Predl R, Steindl F, et al. A Broadly Neutralizing Human Monoclonal Antibody Against Gp41 of Human Immunodeficiency Virus Type 1. AIDS Res Hum Retroviruses (1994) 10p:1651-8. doi: 10.1089/aid.1994.10.1651

26. Muster T, Guinea R, Trkola A, Purtscher M, Klima A, Steindl F, et al. CrossNeutralizing Activity Against Divergent Human Immunodeficiency Virus Type 1 Isolates Induced by the Gp41 Sequence ELDKWAS. J Virol (1994) 68 (6):4031-4. doi: 10.1128/jvi.68.6.4031-4034.1994

27. Burton DR, Hangartner L. Broadly Neutralizing Antibodies to HIV and Their Role in Vaccine Design. Annu Rev Immunol (2016) 34:635-59. doi: 10.1146/annurev-immunol-041015-055515

28. Munro JB, Mothes W. Structure and Dynamics of the Native HIV-1 Env Trimer. J Virol (2015) 89(11):5752-5. doi: 10.1128/JVI.03187-14

29. McCoy LE. The Expanding Array of HIV Broadly Neutralizing Antibodies. Retrovirology (2018) 15(1):70. doi: 10.1186/s12977-018-0453-y

30. Bonsignori M, Liao H-X, Gao F, Williams WB, Munir Alam S, Montefiori DC, et al. Antibody-Virus Co-Evolution in HIV Infection: Paths for HIV Vaccine Development. Immunological Rev (2017) 275:145-60. doi: 10.1111/ imr.12509

31. Yuan M, Cottrell CA, Ozorowski G, van Gils MJ, Kumar S, Wu NC, et al. Conformational Plasticity in the HIV-1 Fusion Peptide Facilitates Recognition by Broadly Neutralizing Antibodies. Cell Host Microbe (2019) 25(6):873-83.e5. doi: 10.1016/j.chom.2019.04.011

32. Pegu A, Yang Z-Y, Boyington JC, Wu L, Ko S-Y, Schmidt SD, et al. Neutralizing Antibodies to HIV-1 Envelope Protect More Effectively In Vivo Than Those to the CD4 Receptor. Sci Transl Med (2014) 6 (243):243ra88. doi: 10.1126/scitranslmed.3008992

33. Barouch DH, Whitney JB, Moldt B, Klein F, Oliveira TY, Liu J, et al. Therapeutic Efficacy of Potent Neutralizing HIV-1-Specific Monoclonal Antibodies in SHIV-Infected Rhesus Monkeys. Nature (2013) 503 (7475):224-8. doi: 10.1038/nature12744

34. Gautam R, Nishimura Y, Pegu A, Nason MC, Klein F, Gazumyan A, et al. A Single Injection of Anti-HIV-1 Antibodies Protects Against Repeated SHIV Challenges. Nature (2016) 533(7601):105-9. doi: 10.1038/nature17677

35. Moldt B, Rakasz EG, Schultz N, Chan-Hui P-Y, Swiderek K, Weisgrau KL, et al. Highly Potent Hiv-Specific Antibody Neutralization In Vitro Translates Into Effective Protection Against Mucosal Shiv Challenge In Vivo. Proc Natl Acad Sci (2012) 109:18921-5. doi: 10.1073/pnas.1214785109
36. Sok D, Burton DR. Publisher Correction: Recent Progress in Broadly Neutralizing Antibodies to HIV. Nat Immunol (2019) 20(3):374. doi: 10.1038/s41590-019-0329-x

37. Bournazos S, Klein F, Pietzsch J, Seaman MS, Nussenzweig MC, Ravetch JV. Broadly Neutralizing Anti-HIV-1 Antibodies Require Fc Effector Functions for In Vivo Activity. Cell (2014) 158(6):1243-53. doi: 10.1016/j.cell.2014.08.023

38. Hessell AJ, Hangartner L, Hunter M, Havenith CEG, Beurskens FJ, Bakker JM, et al. Fc Receptor But Not Complement Binding Is Important in Antibody Protection Against HIV. Nature (2007) 449(7158):101-4. doi: 10.1038/nature06106

39. Nimmerjahn F, Ravetch JV. Fcgamma Receptors as Regulators of Immune Responses. Nat Rev Immunol (2008) 8(1):34-47. doi: 10.1038/nri2206

40. Nimmerjahn F, Gordan S, Lux A. Fcyr Dependent Mechanisms of Cytotoxic, Agonistic, and Neutralizing Antibody Activities. Trends Immunol (2015) 36 (6):325-36. doi: 10.1016/j.it.2015.04.005

41. Bruhns P. Properties of Mouse and Human Igg Receptors and Their Contribution to Disease Models. Blood (2012) 119(24):5640-9. doi: 10.1182/blood-2012-01-380121

42. Bryceson YT, March ME, Ljunggren H-G, Long EO. Activation, Coactivation, and Costimulation of Resting Human Natural Killer Cells. Immunol Rev (2006) 214:73-91. doi: 10.1111/j.1600-065X.2006.00457.x

43. Belizário JE, Neyra JM, Rodrigues MFS. When and How NK Cell-Induced Programmed Cell Death Benefits Immunological Protection Against Intracellular Pathogen Infection. Innate Immun (2018) 24:452-65. doi: $10.1177 / 1753425918800200$

44. Prager I, Watzl C. Mechanisms of Natural Killer Cell-Mediated Cellular Cytotoxicity. J Leukoc Biol (2019) 105(6):1319-29. doi: 10.1002/JLB.MR0718$269 \mathrm{R}$

45. Lu LL, Suscovich TJ, Fortune SM, Alter G. Beyond Binding: Antibody Effector Functions in Infectious Diseases. Nat Rev Immunol (2018) 18(1):4661. doi: $10.1038 /$ nri.2017.106

46. Dunkelberger JR, Song W-C. Complement and its Role in Innate and Adaptive Immune Responses. Cell Res (2010) 20(1):34-50. doi: 10.1038/ cr.2009.139

47. Merle NS, Church SE, Fremeaux-Bacchi V, Roumenina LT. Complement System Part I - Molecular Mechanisms of Activation and Regulation. Front Immunol (2015) 6:262. doi: 10.3389/fimmu.2015.00262

48. Karasavvas N, Billings E, Rao M, Williams C, Zolla-Pazner S, Bailer RT, et al. The Thai Phase III HIV Type 1 Vaccine Trial (RV144) Regimen Induces Antibodies That Target Conserved Regions Within the V2 Loop of Gp120. AIDS Res Hum Retroviruses (2012) 28(11):1444-57. doi: 10.1089/aid.2012.0103

49. Chung AW, Crispin M, Pritchard L, Robinson H, Gorny MK, Yu X, et al. Identification of Antibody Glycosylation Structures That Predict Monoclonal Antibody Fc-Effector Function. AIDS (2014) 28(17):2523-30. doi: 10.1097/QAD.0000000000000444

50. Yates NL, Liao H-X, Fong Y, deCamp A, Vandergrift NA, Williams WT, et al. Vaccine-Induced Env V1-V2 Igg3 Correlates With Lower HIV-1 Infection Risk and Declines Soon After Vaccination. Sci Transl Med (2014) 6(228):228ra39. doi: 10.1126/scitranslmed.3007730

51. Haynes BF, Gilbert PB, McElrath MJ, Zolla-Pazner S, Tomaras GD, Alam $\mathrm{SM}$, et al. Immune-Correlates Analysis of an HIV-1 Vaccine Efficacy Trial. $N$ Engl J Med (2012) 366(14):1275-86. doi: 10.1056/NEJMoa1113425

52. Bradley T, Pollara J, Santra S, Vandergrift N, Pittala S, Bailey-Kellogg C, et al. Pentavalent Hiv-1 Vaccine Protects Against Simian-Human Immunodeficiency Virus Challenge. Nat Commun (2017) 8:15711. doi: 10.1038/ncomms15711

53. Andersen-Nissen E, Fiore-Gartland A, Ballweber Fleming L, Carpp LN, Naidoo AF, Harper MS, et al. Innate Immune Signatures to a PartiallyEfficacious HIV Vaccine Predict Correlates of HIV-1 Infection Risk. PloS Pathog (2021) 17(3):e1009363. doi: 10.1371/journal.ppat.1009363

54. Ackerman ME, Mikhailova A, Brown EP, Dowell KG, Walker BD, BaileyKellogg C, et al. Polyfunctional Hiv-Specific Antibody Responses are Associated With Spontaneous Hiv Control. PloS Pathog (2016) 12(1): e1005315. doi: 10.1371/journal.ppat.1005315

55. Dugast A-S, Chan Y, Hoffner M, Licht A, Nkolola J, Li H, et al. Lack of Protection Following Passive Transfer of Polyclonal Highly Functional LowDose Non-Neutralizing Antibodies. PloS One (2014) 9(5):e97229. doi: 10.1371/journal.pone.0097229 
56. Burton DR, Hessell AJ, Keele BF, Klasse PJ, Ketas TA, Moldt B, et al. Limited or No Protection by Weakly or Nonneutralizing Antibodies Against Vaginal SHIV Challenge of Macaques Compared With a Strongly Neutralizing Antibody. Proc Natl Acad Sci (2011) 108:11181-6. doi: 10.1073/ pnas. 1103012108

57. Shingai M, Donau OK, Plishka RJ, Buckler-White A, Mascola JR, Nabel GJ, et al. Passive Transfer of Modest Titers of Potent and Broadly Neutralizing Anti-HIV Monoclonal Antibodies Block SHIV Infection in Macaques. J Exp Med (2014) 211(10):2061-74. doi: 10.1084/jem.20132494

58. Moldt B, Le KM, Carnathan DG, Whitney JB, Schultz N, Lewis MG, et al. Neutralizing Antibody Affords Comparable Protection Against Vaginal and Rectal Simian/Human Immunodeficiency Virus Challenge in Macaques. AIDS (2016) 30(10):1543-51. doi: 10.1097/QAD.0000000000001102

59. Rudicell RS, Kwon YD, Ko S-Y, Pegu A, Louder MK, Georgiev IS, et al. Enhanced Potency of a Broadly Neutralizing HIV-1 Antibody In Vitro Improves Protection Against Lentiviral Infection In Vivo. J Virol (2014) 88 (21):12669-82.

60. Ko S-Y, Pegu A, Rudecill RS, Yang Z-Y, Joyce MG, Chen X, et al. Enhanced Neonatal Fc Receptor Function Improves Protection Against Primate SHIV Infection. Nature (2014) 514(7524):642-5. doi: 10.1038/nature13612

61. Hangartner L, Beauparlant D, Rakasz E, Nedellec R, Hozé N, McKenney K, et al. Effector Function Does Not Contribute to Protection From Virus Challenge by a Highly Potent HIV Broadly Neutralizing Antibody in Nonhuman Primates. Sci Transl Med (2021) 13(585). doi: 10.1126/ scitranslmed.abe3349

62. Parsons MS, Lee WS, Kristensen AB, Amarasena T, Khoury G, Wheatley AK, et al. Fc-Dependent Functions are Redundant to Efficacy of Anti-HIV Antibody PGT121 in Macaques. J Clin Invest. (2019) 129(1):182-91. doi: 10.1172/JCI122466

63. Lu C-L, Murakowski DK, Bournazos S, Schoofs T, Sarkar D, HalperStromberg A, et al. Enhanced Clearance of HIV-1-Infected Cells by Broadly Neutralizing Antibodies Against HIV-1 In Vivo. Science (2016) 352(6288):1001-4. doi: 10.1126/science.aaf1279

64. Mujib S, Liu J, Rahman AKMN-U, Schwartz JA, Bonner P, Yue FY, et al. Comprehensive Cross-Clade Characterization of Antibody-Mediated Recognition, Complement-Mediated Lysis, and Cell-Mediated Cytotoxicity of HIV-1 Envelope-Specific Antibodies Toward Eradication of the HIV-1 Reservoir. J Virol (2017) 91(16):e00634-17. doi: 10.1128/JVI.00634-17

65. von Bredow B, Arias JF, Heyer LN, Moldt B, Le K, Robinson JE, et al. Comparison of Antibody-Dependent Cell-Mediated Cytotoxicity and Virus Neutralization by HIV-1 Env-Specific Monoclonal Antibodies. J Virol (2016) 90(13):6127-39. doi: 10.1128/JVI.00347-16

66. von Bredow B, Andrabi R, Grunst M, Grandea AG 3rd, Le K, Song G, et al. Differences in the Binding Affinity of an HIV-1 V2 Apex-Specific Antibody for the SIV Envelope Glycoprotein Uncouple Antibody-Dependent Cellular Cytotoxicity From Neutralization. MBio (2019) 10(4):e01255-19. doi: $10.1128 / \mathrm{mBio} .01255-19$

67. Bonsignori M, Pollara J, Moody MA, Alpert MD, Chen X, Hwang K-K, et al. Antibody-Dependent Cellular Cytotoxicity-Mediating Antibodies From an HIV1 Vaccine Efficacy Trial Target Multiple Epitopes and Preferentially Use the VH1 Gene Family. J Virol (2012) 86(21):11521-32. doi: 10.1128/JVI.01023-12

68. Acharya P, Tolbert WD, Gohain N, Wu X, Yu L, Liu T, et al. Structural Definition of an Antibody-Dependent Cellular Cytotoxicity Response Implicated in Reduced Risk for HIV-1 Infection. J Virol (2014) 88 (21):12895-906. doi: 10.1128/JVI.02194-14

69. Bruel T, Guivel-Benhassine F, Amraoui S, Malbec M, Richard L, Bourdic K, et al. Elimination of HIV-1-Infected Cells by Broadly Neutralizing Antibodies. Nat Commun (2016) 7:10844. doi: 10.1038/ncomms10844

70. Lu J, Chu J, Zou Z, Hamacher NB, Rixon MW, Sun PD. Structure of Fcyri in Complex With Fc Reveals the Importance of Glycan Recognition for HighAffinity Igg Binding. Proc Natl Acad Sci U S A. (2015) 112(3):833-8. doi: 10.1073/pnas.1418812112

71. Subedi GP, Barb AW. The Immunoglobulin G1 N-Glycan Composition Affects Binding to Each Low Affinity Fc $\gamma$ Receptor. $m A$ As (2016) 8:1512-24. doi: 10.1080/19420862.2016.1218586

72. Subedi GP, Barb AW. The Structural Role of Antibody N-Glycosylation in Receptor Interactions. Structure (2015) 23(9):1573-83. doi: 10.1016/ j.str.2015.06.015
73. Murin CD. Considerations of Antibody Geometric Constraints on NK Cell Antibody Dependent Cellular Cytotoxicity. Front Immunol (2020) 11:1635. doi: 10.3389/fimmu.2020.01635

74. Murin CD, Wilson IA, Ward AB. Antibody Responses to Viral Infections: A Structural Perspective Across Three Different Enveloped Viruses. Nat Microbiol (2019) 4(5):734-47. doi: 10.1038/s41564-019-0392-y

75. Richardson SI, Lambson BE, Crowley AR, Bashirova A, Scheepers C, Garrett N, et al. Igg3 Enhances Neutralization Potency and Fc Effector Function of an HIV V2-Specific Broadly Neutralizing Antibody [Internet. PloS Pathog (2019) 15:e1008064. doi: 10.1371/journal.ppat.1008064

76. Stapleton NM, Andersen JT, Stemerding AM, Bjarnarson SP, Verheul RC, Gerritsen J, et al. Competition for Fcrn-Mediated Transport Gives Rise to Short Half-Life of Human Igg3 and Offers Therapeutic Potential. Nat Commun (2011) 2:599. doi: 10.1038/ncomms1608

77. Chu TH, Crowley AR, Backes I, Chang C, Tay M, Broge T, et al. Hinge Length Contributes to the Phagocytic Activity of HIV-Specific Igg1 and Igg3 Antibodies. PloS Pathog (2020) 16(2):e1008083. doi: 10.1371/ journal.ppat.1008083

78. Liu R, Oldham R, Teal E, Beers S, Cragg M. Fc-Engineering for Modulated Effector Functions-Improving Antibodies for Cancer Treatment. Antibodies (2020) 9:64. doi: 10.3390/antib9040064

79. Shields RL, Namenuk AK, Hong K, Meng YG, Rae J, Briggs J, et al. High Resolution Mapping of the Binding Site on Human Iggl for Fc Gamma RI, Fc Gamma RII, Fc Gamma RIII, and Fcrn and Design of Igg1 Variants With Improved Binding to the Fc Gamma R. J Biol Chem (2001) 276(9):6591-604. doi: 10.1074/jbc.M009483200

80. Lazar GA, Dang W, Karki S, Vafa O, Peng JS, Hyun L, et al. Engineered Antibody Fc Variants With Enhanced Effector Function. Proc Natl Acad Sci (2006) 103:4005-10. doi: 10.1073/pnas.0508123103

81. Richards JO, Karki S, Lazar GA, Chen H, Dang W, Desjarlais JR. Optimization of Antibody Binding to Fcgammariia Enhances Macrophage Phagocytosis of Tumor Cells. Mol Cancer Ther (2008) 7(8):2517-27. doi: 10.1158/1535-7163.MCT-08-0201

82. Stavenhagen JB, Gorlatov S, Tuaillon N, Rankin CT, Li H, Burke S, et al. FC Optimization of Therapeutic Antibodies Enhances Their Ability to Kill Tumor Cells In Vitro and Controls Tumor Expansion In Vivo via LowAffinity Activating Fc $\gamma$ Receptors. Cancer Res (2007) 67:8882-90. doi: 10.1158/0008-5472.can-07-0696

83. Ahmed AA, Keremane SR, Vielmetter J, Bjorkman PJ. Structural Characterization of GASDALIE Fc Bound to the Activating Fc Receptor Fcyriiia. J Struct Biol (2016) 194(1):78-89. doi: 10.1016/j.jsb.2016.02.001

84. Yamane-Ohnuki N, Kinoshita S, Inoue-Urakubo M, Kusunoki M, Iida S, Nakano R, et al. Establishment of FUT8 Knockout Chinese Hamster Ovary Cells: An Ideal Host Cell Line for Producing Completely Defucosylated Antibodies With Enhanced Antibody-Dependent Cellular Cytotoxicity. Biotechnol Bioeng. (2004) 87(5):614-22. doi: 10.1002/bit.20151

85. Gilbert PB, Juraska M, deCamp AC, Karuna S, Edupuganti S, Mgodi N, et al. Basis and Statistical Design of the Passive HIV-1 Antibody Mediated Prevention (AMP) Test-of-Concept Efficacy Trials. Stat Commun Infect Dis (2017) 9(1). doi: 10.1515/scid-2016-0001

86. Gilbert PB. Ongoing Vaccine and Monoclonal Antibody HIV Prevention Efficacy Trials and Considerations for Sequel Efficacy Trial Designs. Stat Commun Infect Diseases. (2019) 11. doi: 10.1515/scid-2019-0003

87. McFarland EJ, Cunningham CK, Muresan P, Capparelli EV, Perlowski C, Morgan P, et al. Safety, Tolerability, and Pharmacokinetics of a Long-Acting Broadly Neutralizing HIV-1 Monoclonal Antibody VRC01LS in HIV-1Exposed Newborn Infants. J Infect Dis (2021). doi: 10.1093/infdis/jiab229

88. Samulski RJ, Muzyczka N. AAV-Mediated Gene Therapy for Research and Therapeutic Purposes. Annu Rev Virol (2014) 1(1):427-51. doi: 10.1146/ annurev-virology-031413-085355

89. Atchison RW, Casto BC, McD. Hammon W. Adenovirus-Associated Defective Virus Particles. Science (1965) 149p:754-5. doi: 10.1126/ science.149.3685.754

90. Buller RML, Janik JE, Sebring ED, Rose JA. Herpes Simplex Virus Types 1 and 2 Completely Help Adenovirus-Associated Virus Replication. J Virol (1981) 40:241-7. doi: 10.1128/jvi.40.1.241-247.1981

91. Urabe M, Nakakura T, Xin K-Q, Obara Y, Mizukami H, Kume A, et al. Scalable Generation of High-Titer Recombinant Adeno-Associated Virus 
Type 5 in Insect Cells. J Virol (2006) 80:1874-85. doi: 10.1128/jvi.80.4.18741885.2006

92. Li C, Jude Samulski R. Engineering Adeno-Associated Virus Vectors for Gene Therapy. Nat Rev Genet (2020) 21:255-72. doi: 10.1038/s41576-019-0205-4

93. Sonntag F, Schmidt K, Kleinschmidt JA. A Viral Assembly Factor Promotes AAV2 Capsid Formation in the Nucleolus. Proc Natl Acad Sci (2010) 107:10220-5. doi: 10.1073/pnas.1001673107

94. King JA. DNA Helicase-Mediated Packaging of Adeno-Associated Virus Type 2 Genomes Into Preformed Capsids. EMBO J (2001) 20:3282-91. doi: 10.1093/emboj/20.12.3282

95. Sonntag F, Bleker S, Leuchs B, Fischer R, Kleinschmidt JA. AdenoAssociated Virus Type 2 Capsids With Externalized VP1/VP2 Trafficking Domains are Generated Prior to Passage Through the Cytoplasm and are Maintained Until Uncoating Occurs in the Nucleus. J Virol (2006) 80:11040-54. doi: 10.1128/jvi.01056-06

96. Girod A, Wobus CE, Zádori Z, Ried M, Leike K, Tijssen P, et al. The VP1 Capsid Protein of Adeno-Associated Virus Type 2 is Carrying a Phospholipase A2 Domain Required for Virus Infectivity. J Gen Virol (2002) 83:973-8. doi: 10.1099/0022-1317-83-5-973

97. Becerra SP, Koczot F, Fabisch P, Rose JA. Synthesis of Adeno-Associated Virus Structural Proteins Requires Both Alternative Mrna Splicing and Alternative Initiations From a Single Transcript. J Virol (1988) 62:274554. doi: 10.1128 /jvi.62.8.2745-2754.1988

98. Ogden PJ, Kelsic ED, Sinai S, Church GM. Comprehensive AAV Capsid Fitness Landscape Reveals a Viral Gene and Enables Machine-Guided Design. Science (2019) 366(6469):1139-43. doi: 10.1126/science.aaw2900

99. Hammond SL, Leek AN, Richman EH, Tjalkens RB. Cellular Selectivity of AAV Serotypes for Gene Delivery in Neurons and Astrocytes by Neonatal Intracerebroventricular Injection. PloS One (2017) 12(12):e0188830. doi: 10.1371/journal.pone.0188830

100. Wang D, Tai PWL, Gao G. Adeno-Associated Virus Vector as a Platform for Gene Therapy Delivery. Nat Rev Drug Discov (2019) 18(5):358-78. doi: 10.1038/s41573-019-0012-9

101. Kotin RM, Siniscalco M, Samulski RJ, Zhu XD, Hunter L, Laughlin CA, et al. Site-Specific Integration by Adeno-Associated Virus. Proc Natl Acad Sci U S A (1990) 87(6):2211-5. doi: 10.1073/pnas.87.6.2211

102. Samulski RJ, Zhu X, Xiao X, Brook JD, Housman DE, Epstein N, et al. Targeted Integration of Adeno-Associated Virus (AAV) Into Human Chromosome 19. EMBO J (1991) 10:3941-50. doi: 10.1002/j.1460-2075.1991.tb04964.x

103. Hüser D, Weger S, Heilbronn R. Kinetics and Frequency of AdenoAssociated Virus Site-Specific Integration Into Human Chromosome 19 Monitored by Quantitative Real-Time PCR. J Virol (2002) 76:7554-9. doi: 10.1128 /jvi.76.15.7554-7559.2002

104. Schultz BR, Chamberlain JS. Recombinant Adeno-Associated Virus Transduction and Integration. Mol Ther (2008) 16:1189-99. doi: 10.1038/ mt.2008.103

105. Chamberlain K, Riyad JM, Weber T. Expressing Transgenes That Exceed the Packaging Capacity of Adeno-Associated Virus Capsids. Hum Gene Ther Methods (2016) 27(1):1-12. doi: 10.1089/hgtb.2015.140

106. Duan D, Sharma P, Yang J, Yue Y, Dudus L, Zhang Y, et al. Circular Intermediates of Recombinant Adeno-Associated Virus Have Defined Structural Characteristics Responsible for Long-Term Episomal Persistence in Muscle Tissue. J Virol (1998) 72(11):8568-77. doi: 10.1128/ JVI.72.11.8568-8577.1998

107. Duan D, Yan Z, Yue Y, Engelhardt JF. Structural Analysis of AdenoAssociated Virus Transduction Circular Intermediates. Virol (1999) 261 (1):8-14. doi: 10.1006/viro.1999.9821

108. Kuzmin DA, Shutova MV, Johnston NR, Smith OP, Fedorin VV, Kukushkin YS, et al. The Clinical Landscape for AAV Gene Therapies. Nat Rev Drug Discovery (2021) 20(3):173-4. doi: 10.1038/d41573-021-00017-7

109. Fang J, Yi S, Simmons A, Tu GH, Nguyen M, Harding TC, et al. An Antibody Delivery System for Regulated Expression of Therapeutic Levels of Monoclonal Antibodies In Vivo. Mol Ther (2007) 15(6):1153-9. doi: 10.1038/sj.mt.6300142

110. Johnson PR, Schnepp BC, Zhang J, Connell MJ, Greene SM, Yuste E, et al. Vector-Mediated Gene Transfer Engenders Long-Lived Neutralizing Activity and Protection Against SIV Infection in Monkeys. Nat Med (2009) 15(8):901-6. doi: 10.1038/nm.1967

111. van den Berg FT, Makoah NA, Ali SA, Scott TA, Mapengo RE, Mutsvunguma LZ, et al. AAV-Mediated Expression of Broadly Neutralizing and Vaccine-Like Antibodies Targeting the HIV-1 Envelope V2 Region. Mol Ther Methods Clin Dev (2019) 14:100-12. doi: 10.1016/ j.omtm.2019.06.002

112. Saunders KO, Wang L, Joyce MG, Yang Z-Y, Balazs AB, Cheng C, et al. Broadly Neutralizing Human Immunodeficiency Virus Type 1 Antibody Gene Transfer Protects Nonhuman Primates From Mucosal Simian-Human Immunodeficiency Virus Infection. J Virol (2015) 89(16):8334-45. doi: 10.1128/JVI.00908-15

113. Welles HC, Jennewein MF, Mason RD, Narpala S, Wang L, Cheng C, et al. Vectored Delivery of Anti-SIV Envelope Targeting Mab via AAV8 Protects Rhesus Macaques From Repeated Limiting Dose Intrarectal Swarm Sivsme660 Challenge. PloS Pathog (2018) 14(12):e1007395. doi: 10.1371/ journal.ppat.1007395

114. Priddy FH, Lewis DJM, Gelderblom HC, Hassanin H, Streatfield C, LaBranche C, et al. Adeno-Associated Virus Vectored Immunoprophylaxis to Prevent HIV in Healthy Adults: A Phase 1 Randomised Controlled Trial [Internet]. Lancet HIV (2019) 6:e230-9. doi: 10.1016/s2352-3018(19)30003-7

Conflict of Interest: The authors declare that the research was conducted in the absence of any commercial or financial relationships that could be construed as a potential conflict of interest.

Publisher's Note: All claims expressed in this article are solely those of the authors and do not necessarily represent those of their affiliated organizations, or those of the publisher, the editors and the reviewers. Any product that may be evaluated in this article, or claim that may be made by its manufacturer, is not guaranteed or endorsed by the publisher.

Copyright (๑) 2021 Phelps and Balazs. This is an open-access article distributed under the terms of the Creative Commons Attribution License (CC BY). The use, distribution or reproduction in other forums is permitted, provided the original author(s) and the copyright owner(s) are credited and that the original publication in this journal is cited, in accordance with accepted academic practice. No use, distribution or reproduction is permitted which does not comply with these terms. 